\title{
DISCLAIMER
}

This report was prepared as an account of work sponsored by an agency of the United States Government. Neither the United States Government nor any agency thereof, not any of their employees, makes any warranty, express or implied, or assumes any legal liebility or responsibility for the accuracy, completeness, or usefulness of any information, apparatus, product, or process disclosed, or represents that its use wou?d not infringe privately owned rights. Reference herein to any specific commercial product, process, or servioe by trade name. trademark, manufacturer, or otherwise does not necessarily constitute or imply its endorsement, recommendation, or favoring by the United Slates Government or any agency thereof. The views and opinions of authors expressed herein do not necessarily state or reflect those of the United States Government of any agency thereof.

UCLA-ENG--8605

DE86 012972

UCLA-ENG-8605

PPG-931

\section{Bowing of Solid Breeder Fuel Pins and Multiplier Rods in a Pin-Type Fusion Blanket}

\author{
James P. Blanchard and Nasr M. Ghoniem
}

February 1986

This research was performed under appointment to the Magnetic Fusion Energy Technology Fellowship program administered by Oak Ridge Associated Universities for the U.S. Department of Energy. The support of U.S. Department of Energy, Grant \#DE- $03-$ 80ER52061, to UCLA is appreciated. 


\section{DISCLATER}

This report was prepared as an acco: it of work sponsored by an agency of the United Stites Government. Nefther the United States Governwent nor any agency thereof, nor any of their enployees, nakes any warranty, express or implied, or sesunes any legel Ilablitty or reaponalbility for the accuracy, completeness, or usefulness of any inforetion, apparatus, product, or process disclosed, or represents that 1 ts use would not Infringe privately owned rights. Reference herein to any specific comercial product, process, or service by trade name, tradena-k, manufacturer, or otherwise, does not necessarily constitute or Ioply its endorseweat, recounendation, r favoring by the United States Governent or any agemy thereof. The views and opinfons of authors expressed herein do not necessarily state or reflect those of the Untted States Government or any agency thereof. 


\section{INTRODUCTION}

When a solid breeder is encased in a metal tube, its designer must use analyses of both the deflections and stresses in order to determine the number and type of supports to construct along the rod. For a thorough analysis, one must include such "loads" as thermal expansion, body weight of both the pellets and tube, and swelling. In addition, models for thermal and Irradiation creep must be incorporated to model time-dependent response. For this report, analytical methods will be used to allow use of the most general, up-to-date material models.

The breeder rods, as shown in Fig. la, are modeled as Euler beans whish are simply supported at each end and in the center. The thermal and radiation damage flelds are assumed to be constant along the rod, varying only over the cross section. This leads to symmetry about the central support, allowing analysis of only half the length of the model as shown in Fig. 1b. The applied force per unit length q is equivalent to the weight loading, while arbitrary temperature and swelling varfations over the cross section are also considered.

\section{ANALYSIS}

\subsection{BEAM THEORY}

For a Bernoulli-Euler beau under axial and transverse loadings, the axtal strain $\varepsilon_{z}$ is given by

$$
\varepsilon_{z}=\varepsilon_{0}-x \frac{d^{2} v}{d \xi^{2}}
$$


where $\varepsilon_{0}$ is the strain at the central axis $(x=0)$ and $v$ is the transverse beam deflection [1]. To relate $\varepsilon_{z}$ to the stress $\sigma_{z}$, one requires a constitutive relation, which for a $1-D$ stress state is

$$
\varepsilon_{z}=\frac{\sigma_{z}}{E}+\alpha T+e^{s}+e^{c}
$$

where $\alpha T$, $e^{s}$, and $e^{c}$ represent the therwal, swelling, and creep strains, respectively.

Combining FqB. (1) and (2), multiplying by $x$, and Integrating over the cross section, one finds the following second order equation for the displaceurent:

$$
-E I \frac{d^{2} v}{d \xi^{2}}=M+M_{T}+M_{S}+M_{C}
$$

where $I$ is the moment of Inertia of the cladding cross section, $E$ is its Young's Modulus and

$$
\begin{aligned}
& M=\int x \sigma_{z} d A, \\
& M_{T}=E \int x \alpha T d A \\
& H_{S}=E \int x e^{S} d A, \\
& M_{C}=E \int x e^{c} d A,
\end{aligned}
$$


Using the standard sign conventions, the moment $M$ can be related to $q$; equilibriun requires

$$
\frac{d^{2} M}{d \xi^{2}}+q=0
$$

Integrating $E q .(5)$ twice and using the boundary condition $M(L / 2)=0$, yields

$$
M=C_{1}\left(\xi-\frac{L}{2}\right)-\frac{1}{2} q\left(\xi^{2}-\frac{L^{2}}{4}\right)
$$

where $c_{l}$ is an arbitrary constant. Substituting Eq. (6) into Eq. (3) and integrating twice gives

$$
\begin{aligned}
-E I v= & c_{2} \xi+c_{3}+\frac{1}{2} \xi^{2} C_{1}\left(\frac{\xi}{3}-\frac{L}{2}\right)-\frac{1}{8} \xi^{2} q\left(\frac{1}{3} \xi^{2}-\frac{L^{2}}{2}-\right) \\
& +\left(M_{T}+M_{S}\right) \frac{1}{2} \xi^{2}+\int_{0}^{\xi} \int_{0}^{n} M_{C} d \psi d \eta
\end{aligned}
$$

Using the displacement boundary conditions $v(0)=v^{\prime}(0)=v(L / 2)=0$, the constants are found to be

$$
\begin{aligned}
& c_{2}=c_{3}=0, \\
& c_{l}=\frac{5}{16} q L+\frac{3}{L}\left(M_{T}+M_{S}\right)+\frac{24}{L^{3}} \int_{0}^{L / 2} \int_{0}^{n} M_{C} d \psi d \eta,
\end{aligned}
$$

and Eq. (7) becomes 


$$
\begin{aligned}
E I v= & \frac{1}{4} \xi^{2}\left(1-2 \frac{\xi}{L}\right)\left(M_{T}+M_{S}\right)+\frac{1}{64} \xi^{2} L^{2}\left(I-\frac{4}{3} \frac{\xi}{L}\right)\left(1-2 \frac{\xi}{L}\right) a \\
& +6 \frac{\xi^{2}}{L^{2}}\left(1-\frac{2}{3} \frac{\xi}{L}\right) \int_{0}^{L / 2}\left(\frac{L}{2}-\eta\right) M_{C} d \eta-\int_{0}^{\xi}(\xi-\eta) M_{C} d \eta,
\end{aligned}
$$

where Green's theorem has been used to reduce the double integral in Eq. (7) to a single integra1, i.e.,

$$
\int_{0}^{\xi} \int_{0}^{n} M_{C} d \psi d n=\int_{0}^{\xi}(\xi-n) M_{C} d n
$$

\subsection{STRESSES}

To determine the axtal stress we return to Eq. (2). Substituting Eq. (1) For $\varepsilon_{z}$ and integrating over the cross section, $\varepsilon_{0}$ is found in terms of the axiel forse on a cross section $F$, and the inelastic strains:

$$
\varepsilon_{0}=\frac{F+F_{T}+F_{S}+F_{G}}{E A}
$$

where $A$ is the cross sectional area and

$$
\begin{aligned}
F & =\int \sigma d A, \\
F_{T} & =E \int \alpha T d A, \\
F_{S} & =E \int e^{s} d A, \\
F_{C} & =E \int e^{c} d A,
\end{aligned}
$$


Inserting $\mathrm{Eq} \cdot(11)$ into $\mathrm{Eq} \cdot(2)$ gives

$$
\sigma=\frac{F+F_{T}+F_{S}+F_{C}}{A}-E\left(\alpha T+e^{s}+e^{c}\right)-x E \frac{d^{2} v}{d \xi^{2}}
$$

From Eq. (9), $d^{2} v / d \xi^{2}$ is found to be

$$
\begin{aligned}
E\left[\frac{d^{2} v}{d \xi^{2}}=\right. & \frac{1}{2}(1-6 \xi / L)\left(M_{T}+M_{S}\right) \\
& +L^{2} / 32(1-8 \xi / L)(1-2 \xi / L) q \\
& +12 / L^{2}(1-2 \xi / L) \int_{0}^{L / 2}(L / 2-\eta) M_{C} d n-M_{C},
\end{aligned}
$$

and the stress equation [Eq. (13)] becomes

$$
\begin{aligned}
\sigma= & \frac{F+F_{T}+F_{S}+F_{C}}{A}-E\left(\alpha T+e^{S}+e^{C}\right)-\left(\frac{M_{T}+M_{S}}{2 I}\right) \times\left(1-\frac{6 \xi}{L}\right) \\
& -q L^{2} x / 32 I(1-2 \xi / L)(1-8 \xi / L) \\
& -\frac{12 x}{L^{2}}(1-2 \xi / L) \int_{0}^{L / 2}(L / 2-\eta) M_{C} d \eta+M_{C} x / I .
\end{aligned}
$$

\subsection{CONSTITUTIVE EOUATIONS}

To solve this rod bowing problem, a time-dependent or steady-state thermal field must be determined. To calculate the equivalent moments and forces of Eqs. (4) and (12) also requires equations for swelling and thermal and Irradiation creep in terns of time (or dose) and temperature.

In this study, the swelling of the HT-g cladding was assumed to conform to the following general relation [2] 


$$
\frac{\Delta V}{V}(x)=s\left(\delta-\delta_{I}\right) \exp \left[-\left(\frac{x-425^{\circ} C}{59^{0} C}\right)^{2}\right],
$$

where $S$ is the swelling rate $(\% / \mathrm{dpa}), \delta$ is the dose (dpa), $\delta_{I}$ is the incubation dose (dpa), and $T$ is the cladding temperature $\left({ }^{\circ} \mathrm{C}\right)$. If $\delta$ is less than $\delta_{I}, \Delta V / V$ is taken to be zero. Using data for 2-1/4 Cr-1 No gathered by Gelles and Puigh [3], S and $\delta_{I}$ were chosen to be $0.02 \% / \mathrm{dpa}$ and $90 \mathrm{dpa}$, respectively. A 30-dpa Incuhation dose will also be studied.

Agaln using data from felles and Puigh, Irradlation creep was modeled according to

$$
\frac{d e^{c}}{d \delta}\left(d p a^{-1}\right)=c \sigma^{1.5}
$$

where $C$ was found to be $8.511 \times 10^{-8} \mathrm{dpa}^{-1} \mathrm{MPa}^{-1.5}$.

The themal creep correlation for HT-9 takes a different forn [4]:

$$
\ddot{e}_{t h}^{c}=\frac{2289}{T}\left(|0|-\sigma_{0}\right)^{3} \dot{e x p}\left(-\frac{1.427 \times 10^{4}}{T}\right)
$$

Here $e_{t h}^{c}\left(y r^{-1}\right)$ is the thermal creep rate and $\sigma_{o}$ (MPa) represents a temperature dependent back stress given by

$$
\sigma_{0}=1366.4-1.507 \mathrm{~T},
$$

where $\mathrm{I}$ is the temperature (K). This Eormula predicts no thermal creep for temperatures below $500^{\circ} \mathrm{C}$ and stresses below $200 \mathrm{Ma}$, so 1rradiation creep dominates thermal creep in this analysis. 


\section{RESULTS}

\subsection{BREEDER ROD BOWING}

Excessive deflections in a bank of solid breeder rods can severely impair reactor performance. Relative displacements of neighboring rods can choke off coolant flow paths, leading to hot spots and premature fallure. In extreme cases, the rod sladding may buckle, causing changes in thermal gap conductances, and posstbly tube rupture. Therefore, the peak rod deflections due to thermal, gravitational, and swelling effects must be kept small.

For the rod dimensions and reactor parameters analyzed here, the deflections due to swelling were by far the most severe. The bowing caused by the pellet weight was inconsequential besause of the low dinsity of the breeder and the thermal deflections were also relatively small, even for a 2-m-long rod with only one internal support. The final support spacing will depend on the peak bowing caused by swelling, as well as by the allowable cladding stresses.

\subsection{INITIAL DEFLECTIONS}

The rod bowing due to the pellet welght and thermal field is primarily driven by an azimuthal temperature variation over the cladding's cross section. In the first few breeder pins, the temperature gradient is due mostly to a gradient in the volumetric heating, so the front (plasma side) is hotter than the rear. m the other hand, pins near the back of the blanket are hotter at the rear of the tube because the heat transfer coefficient ts highest there. This basic difference in the thermal fields causes the front 
pins to bow towards the plasma, while the rear pins deflect in the oppofite direction.

The initial deflections of a 2 m-long rod with one internal support are shown In Fig. 2. The ends are assumed to be simply supported, while there is no axtal restraint. The peak deflection is under $0.5 \mathrm{~mm}$, which is negligible. Unfortunately, the swelling defornation is somewhat larger, so additional Internal supports mist be added to reduce the peak displacen.nts to an acceptable level.

The model developed previously features only one internal support, so care must be taken if it is used to analyze multiple internal supports. To approximate the deflections of a rod with $50 \mathrm{~cm}$ between supports, the existing model can be used by setring $L$ equal to $100 \mathrm{~cm}$. The deflclency in this approach is seen in Fig. 2, which shows that the slope continuity conditicd at the center of the rod clearly is not met. Fortunately, the model is conservative because the calculated deflections will be greater than those in the actual blanket. The swelling behavior will deternine the final choice for the number of internal supports.

\subsection{TIME-DEPENDENT BEHAVIOR}

Because the vold swelling of HT-9 has a temperature variation that is Gaussian [Eq. (16)], the thermal gradient over the rod's cross section leads to an even harsher swelling gradient. Hence, one wight expect swelling deformations to be quite severe. As shown in Fig. 3, the peak deflection after elght full power years overwhelmed the inftial deflections, whtch are essentlally zero on this scale. These deflections should be small enough to allow a four year 11fe. 
The effect of the support spacing is shown In FIg. 4 which shows the peak deflections of rods with 100 and $50 \mathrm{~cm}$ between supports. In the case of the swaller spact.ng, the peak deflection is only about $1 \mathrm{~cm}$ after 6 years. Considering that the model overestimates the rod deflections, this should be an adequate chotce for the destgn.

\subsection{REIATIVE BOWING IN DIFEERENT BREEDING ZONES}

The deflections in the first breeder zone differ from those in the second zone for three reasons:

1. The second zone contains stiffer rods because of the larger diameter,

2. The thermal gradients are different, as discussed in Section 3.2 ,

3. The damage rate decreases with distance from the plasma.

All of these factors lead to lower deflections in the back zone.

In Fig. 5, the peak deflections are shown for the Flrst row of each zone. Because of the 90 dpa incubation dose, there is no significant deformation for the first three years. The firgt rod then begins to deflect towards the plasma at a peak rate of about $0.5 \mathrm{~cm} / \mathrm{yr}$, whereas the second rod shows no bowing through five years. The deflections here are quite small, leading to minimal tube contact during five full power years.

This rosy plcture is altered by uncertaintles in the swelling correlation For HT-9. If the incubation dose Is snaller, the cods will hegin to bow significantly at a lower dose and the peak deflections will be larger at a given time. In Fig. 6 we see the peak deflections for a 30 dpa Incubation dose. The first zone begins bowing after about a year and the second zone begins after about two years. Because the two rods are bowing in opposite 
directions, the most faportant rod inceraction will involve the multiplier rods and the first breeder zone.

\subsection{Be MULTIPLIER RODS}

In terms of howing, the multiplfer rcds have two distinct advantages over the breeder sods. First, the multiplier rod is solid, so its moment of inertla is much larger than the breeder rods. Second, the thermal conductivity of Be is much higher than the effective conductivity of the breeder pellet and its cladding, so the temperature gradient over the cross section is mich smaller. The resulting deflections are very small.

For a $2-m-1$ ong Be rod with one internal support and a linear temperature dependence, Eq. (9) predicts a peak deflection of

$$
v_{\text {peak }}=0.015 \Delta \mathrm{T},
$$

where $\Delta T\left({ }^{\circ} \mathrm{C}\right)$ is the front-to-back tewperature difference over the cross section. Thermal calculations similar to those for the breeder rods predict a difference of only $2^{\circ} \mathrm{C}$, Leading to a deflection of less than 1 mm.

Because the temperature is nearly cristant in the Be rods, the swelling gradient w11i depend only on the danage gradfent. The damage gradient is expected to be small in the Individual multiplier rods because of their relatively small diameter, so the Be rod deflections should remain low. More detalled neutronics calculations are required before this assuption is validated. 
4. GONGLUSIONS

The most important outcome of this bowing analysis is the deternination of the number of interal breeder rod supports required for good thermal performance. Aithough many effects were considered, the swelling deformations were the most restrictive in terms of the peak deflections. It appears that three Internal supports should be sufficlent to keep the rod bowing below acceptable levels without significantly ralsing the structure-to-breeder ratio.

The most severe fnteraction problem involved the last mutiplier row and the flrst breeder row. Because the Be Iods deflect very little, this problem can be allevlated by leaving enough space between these two zones. The spactng can be tighter elsewhere. A more detalled analysis of the multiplier rod bowing caused by the damage gradient nust be analyzed before this can be verifled.

\section{ACKNOWLEDGTENTS}

This research was performed under appointment to the Magnetic Fusion Energy Technology Fellowship program admintstered by Oak Ridge Associated Universities for the U.S. Department of Energy. The support of Department of Energy, Contract DE-FG03-BOER52061 to UCLA is apprectated. 
REFERENCES

1. T. H. Lin, Theory of Inelastic Stresses, (Wiley \& Sons, New York, 1968) p. 128.

2. R. W. Conn and N. M. Ghoniem, "Assessment of Ferritic Steels for SteadyState Fusion Reactors," Pusion Reactor Design and Technology, IACA-TC-392/62, (Interrational Atomic Energy Agency, Vienna, 1983) Vol. II, p. 389.

3. D. S. Gelles and R. J. Puigh, Evaluation of Ferritic Alloy Fe-2-1/4 Cr - 1 Mo After Reutron Irradiation-Irradlation Creep and Swelling," Hanford Engineering Development Laboratory Report HEDI-7405 (1983).

4. R. J. Amodeo and N. M. Ghonlen, "Developnent of Design Equations for Ferritic Alloys in Fusion Reactors," Mucl. Engrg, and Design/Fuston, 2 (January 1985) pp. 97-110. 


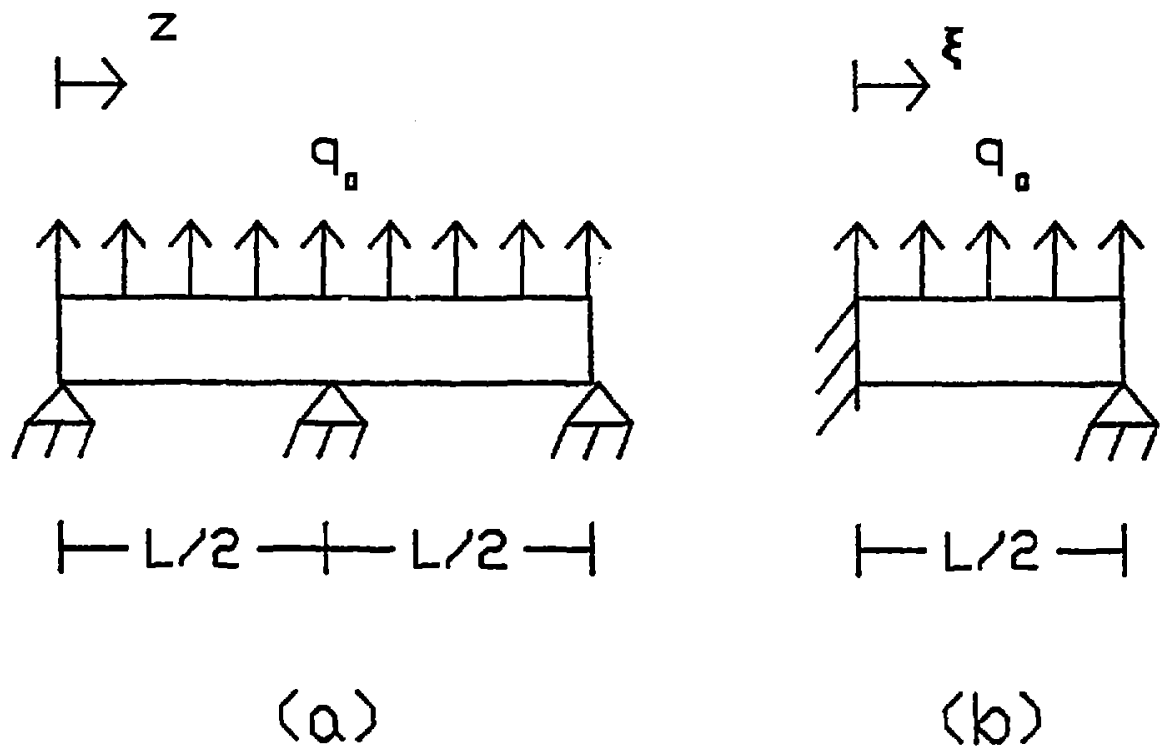

Fig. 1. Beam models used for boring analysis. 


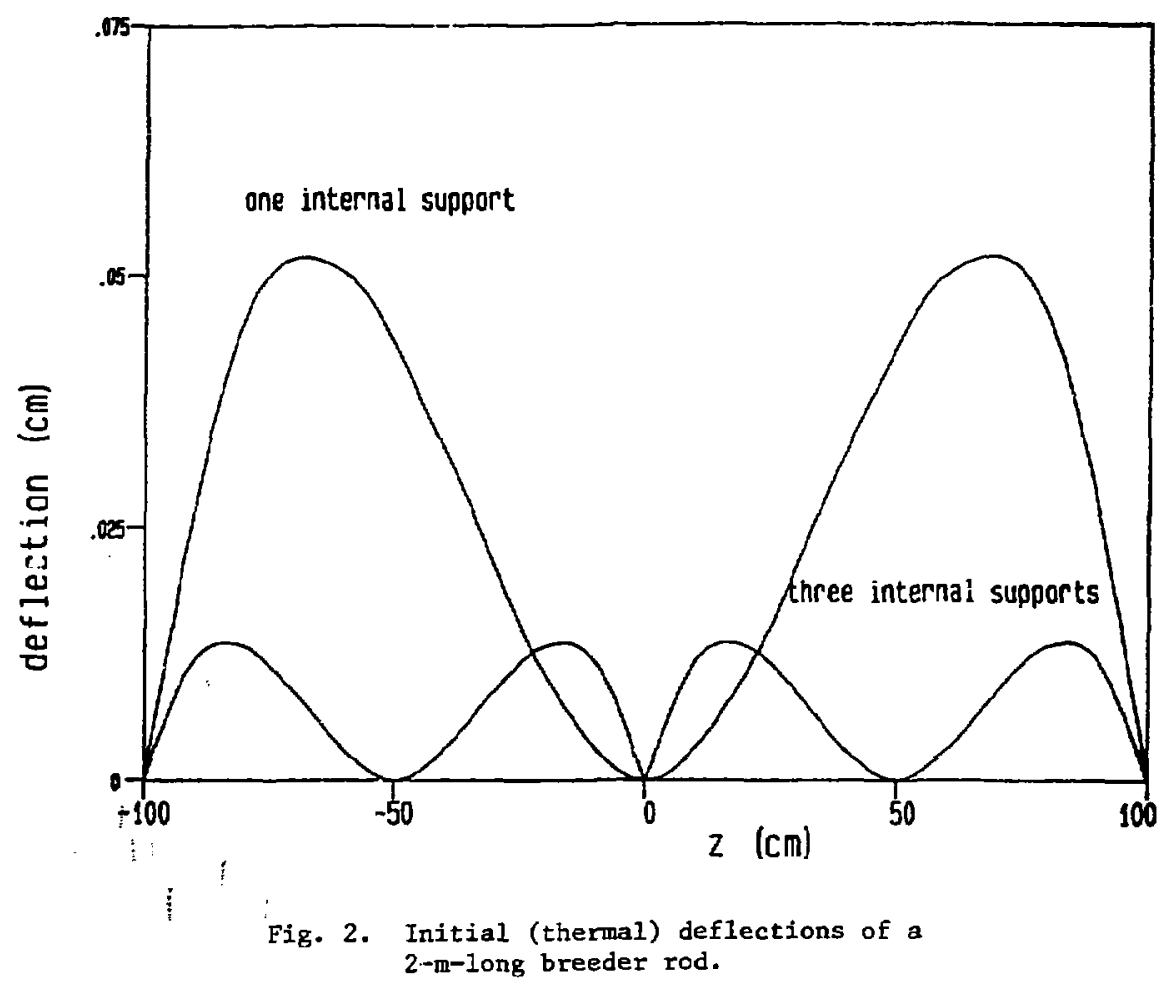




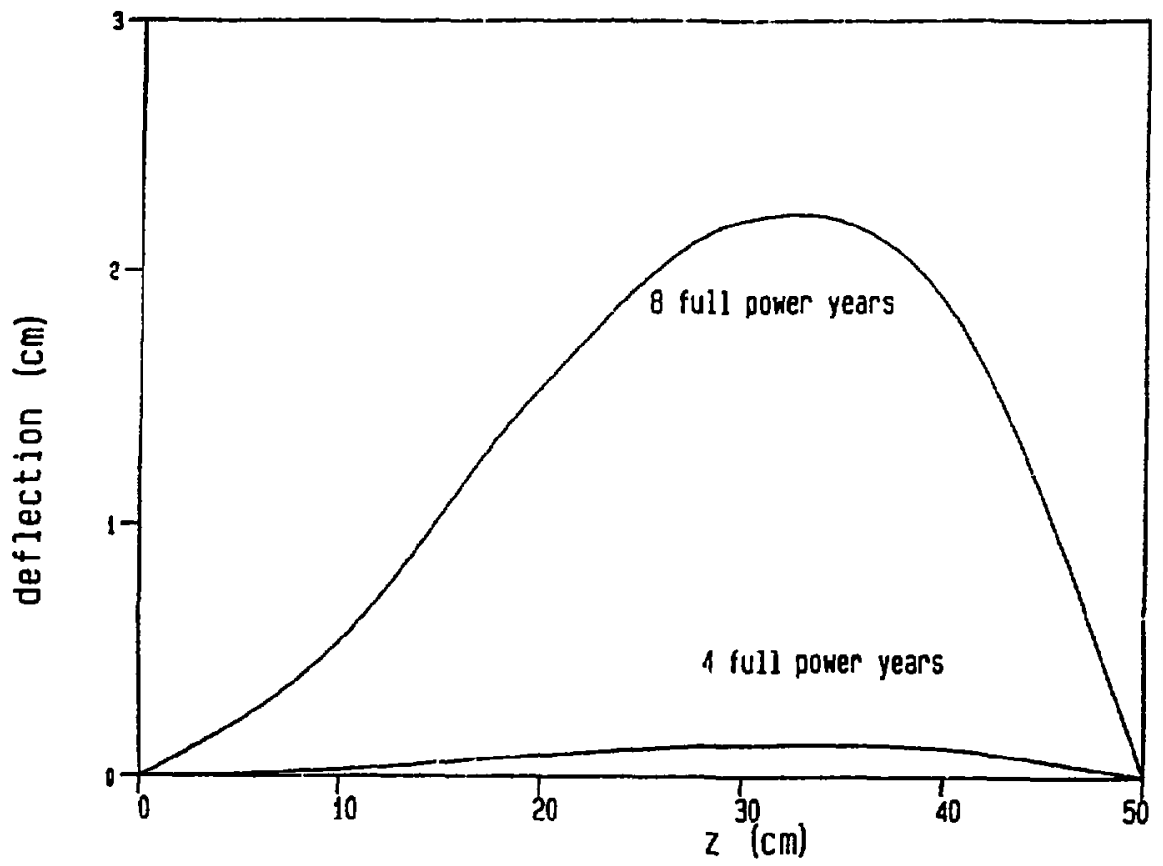

Fig. 3. Rod detlections over eight full-power years. 


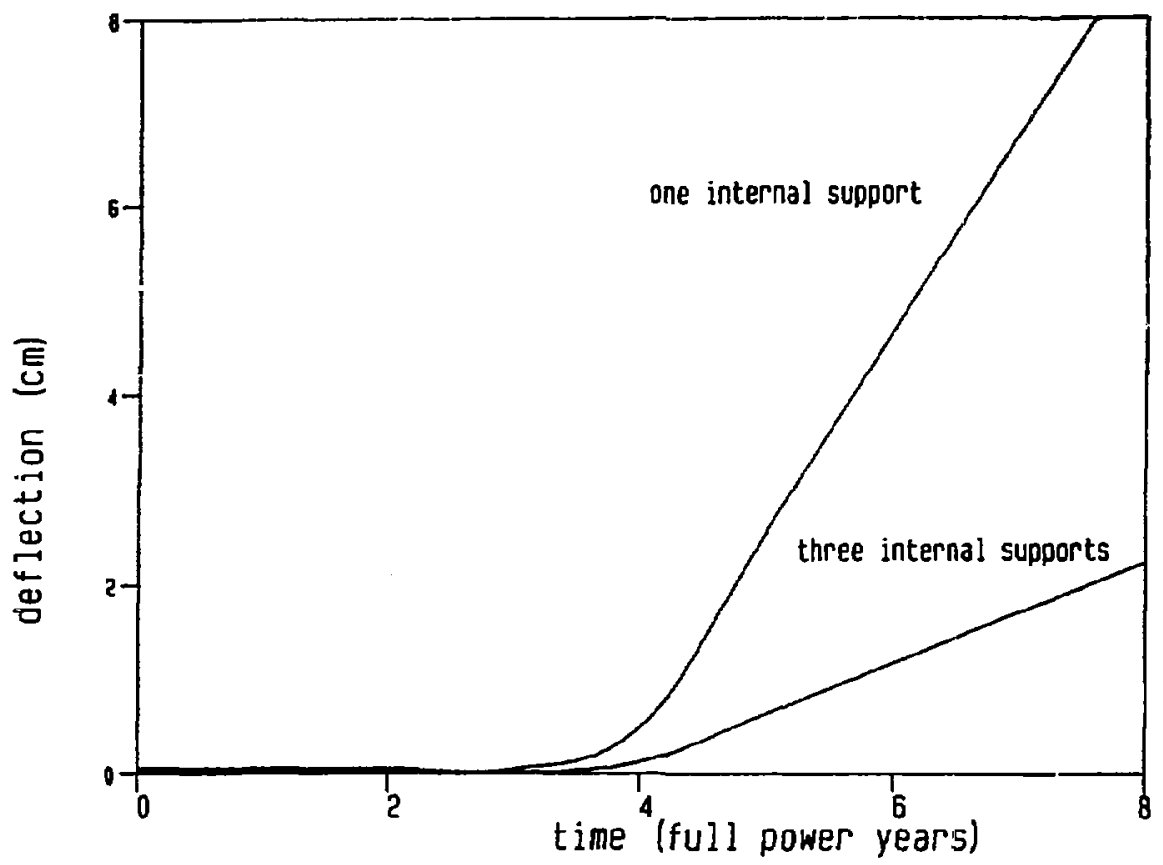

Fig. 4. Bowing of rods with different support spacings. 


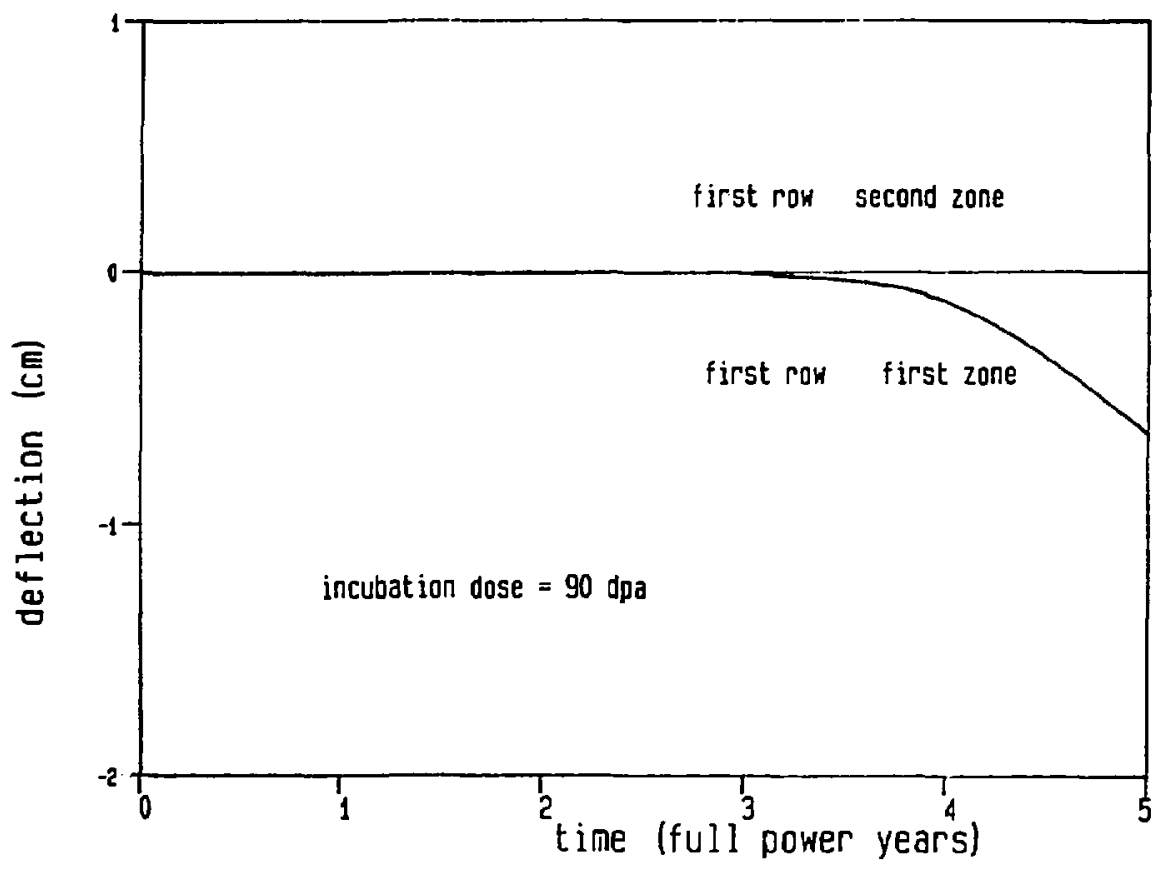

Fig. 5. Comparison of the peak deflections in two different breeder zones 


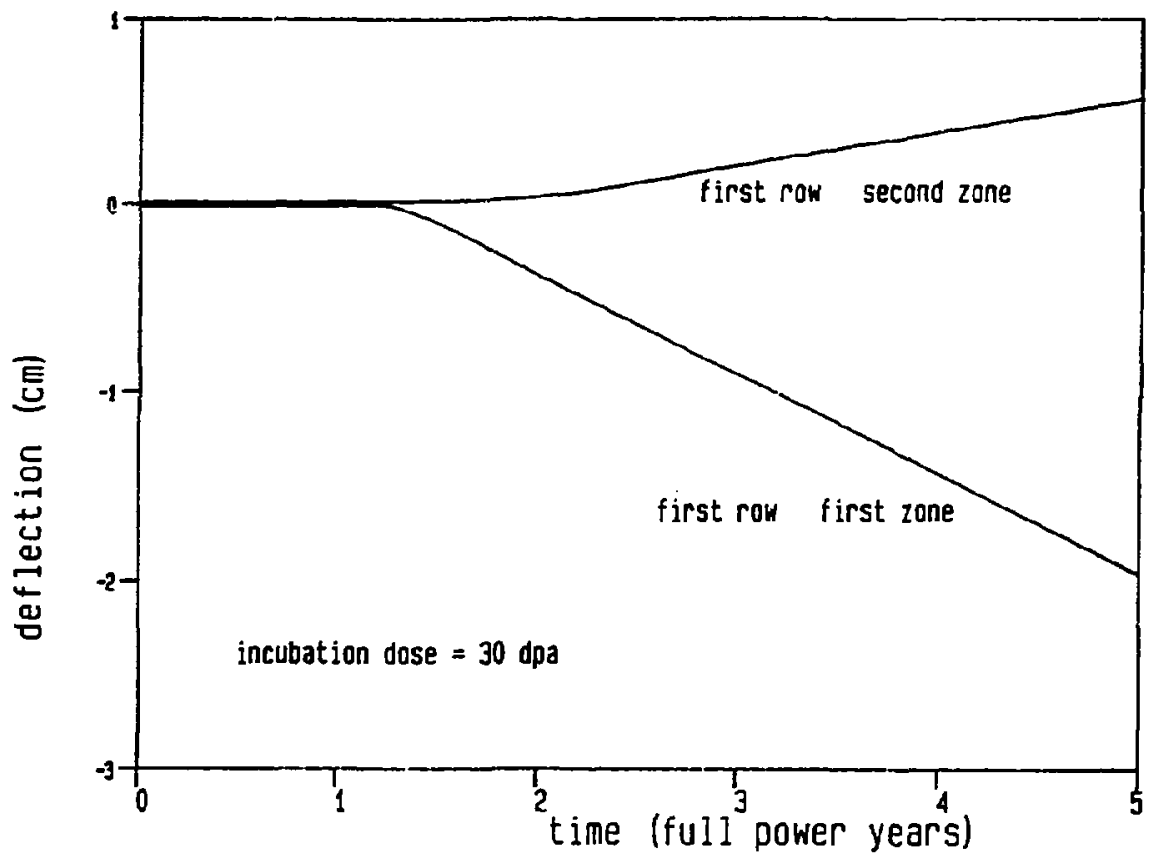

Fig. 6. Peak deflections in two breeder zones with reduced Incubation dose. 